\title{
Aerodynamic Analysis on Proton Preve by Experimental
}

\author{
Mohamad Nor Musa ", Syahrullail Samion, Fairuz Zainal Abidin \\ Faculty of Mechanical Engineering, Universiti Teknologi Malaysia, 81310 UTM Skudai, Johor, \\ Malaysia. \\ *mnormusa@fkm.utm.my
}

Keywords: Aerodynamic, Experimental, Proton Preve, speed, $C_{D}$ value

\begin{abstract}
The purpose of this study is to determine the coefficient drag, $C_{D}$ of the Proton PREVÊ by experimental method using Low Speed Wind Tunnel. All the relevant data are collected through the literature reviews from books and journals. First, the basic thing in aerodynamic is studied. There are two things are concern when studies aerodynamics. They were air flow and vehicle shape which we regard as aerodynamics factor that determine aerodynamic of the vehicle. Fundamental of air flow and vehicle shape is reviewed includes the relationship between air speed with pressure, boundary layer, Reynolds number, drag, lift drag and shape optimization. Wind tunnel is also studied before the experiment. Five selected speed were been tasted during the experiment to determine the $\mathrm{C}_{\mathrm{D}}$ value.
\end{abstract}

\section{Introduction}

Aerodynamic is a studying the motion of air, particularly when it interacts with a solid object such as vehicles, airplane and human [1]. The term aerodynamics can be defined as the science of air in motion. Lift and drag forces are arguably the two most important performance measures studied in aerodynamics [2,3]. One of the most dramatic examples of an aerodynamic device is a Formula 1 racing car. For example the design of front wings, typically, multi-element airfoil section optimized for relatively low-speed air flow is employed with end plates to minimize induced drag. The shape of the rear body engine cover is dictated by the rear wheels and thus narrows to avoid them and also to encourage the flow adjacent to the cover to remain attached. Barge boards were once a primary feature shielding the radiator ducts from the turbulent wake of the front wheels. It is noted that the important design the shape of vehicles into aerodynamic shape is to reduce the air friction in motion [4,5]. As we compare to America car design, they more aerodynamic shapes like Ferrari, Lamborghini and BMW. Malaysia car design is also quiet aerodynamic shape as comparable to overseas car. Aerodynamics force is important because it have great affected both vehicles stability and cost operation. Aerodynamic noise, vibration and poor ventilation give an unfovaurable effect on comfort. Therefore, a vehicle with substantially better aerodynamic will be much more fuel efficient [6]. Proton PREVE is four-door sedan car developed by Malaysia automaker Proton. In this study, the wind tunnel testing is employed using scaled model method. The scale will be 1:15 to the real dimension of Proton PREVE.

\section{Material and Method}

The aim of this project is to calculate the coefficient drag $C_{D}$ for national car Proton PREVÊ. This car has been selected to be studied and tested in the open type mini wind tunnel aeronautic laboratory. It is at least five different speeds to perform on the scaled model in the wind tunnel. The speeds are $10 \mathrm{~m} / \mathrm{s}, 15 \mathrm{~m} / \mathrm{s}, 20 \mathrm{~m} / \mathrm{s}, 25 \mathrm{~m} / \mathrm{s}$ and $30 \mathrm{~m} / \mathrm{s}$. These five speeds are equal to simulate the actual normal air speeds on moving vehicles on the roads. This experiment was conducted in the UTM-Aero Laboratory using Subsonic Plint \& Partners Ltd wind tunnel. For experiment setup, the micro manometer was used as a tool the measured air speed and pressure. The macro manometer is connected to the point 1 and point 2 at the pitot tube. The velocity reading for the test section is 
measured using digital micro manometer based on static pressure difference at contraction chamber. The scaled model is placed in the test section. The model was then mounted on three components balance directly beneath the test section floor. There is a small hole under the test section floor which allows the rod from the three component balance to be attached with the model's underbody in test section. The rod is known as " $P$ " shape of main component in the three component balance system. The model is adjusted in a $x$-direction, $y$-direction and $z$-direction which the model's is normal to the air blow in the wind tunnel. The blower fan is on and waits for 10 min for warming up the engine. Then, the speed of wind tunnel is adjusted by rotating the adjustable speed of wind tunnel. The velocity is set to $10 \mathrm{~m} / \mathrm{s}, 15 \mathrm{~m} / \mathrm{s}, 15 \mathrm{~m} / \mathrm{s}, 20 \mathrm{~m} / \mathrm{s}$ and $30 \mathrm{~m} / \mathrm{s}$. The drag force of the model was measured using the three component balance and recorded in the specialized programmed computer. Finally, the Reynolds number was calculated based on Proton PREVÊ scaled model.

\section{Results and Discussion}

The experiment has been conducted at Subsonic Plint \& Partners Ltd wind tunnel, Aero-lab Universiti Teknologi Malaysia. The scaled model ratio 1:15 Proton Preve was placed in the wind tunnel test section. The ground clearance in this experiment was set to one height 0.012 , while the wind speed in the wind tunnel test section was set to $10 \mathrm{~m} / \mathrm{s}, 12 \mathrm{~m} / \mathrm{s}, 20 \mathrm{~m} / \mathrm{s}, 25 \mathrm{~m} / \mathrm{s}$ and $30 \mathrm{~m} / \mathrm{s}$. The wind tunnel maximum speed reaches the expected velocity which is $30 \mathrm{~m} / \mathrm{s}$. The wind speed range between $10 \mathrm{~m} / \mathrm{s}$ to $30 \mathrm{~m} / \mathrm{s}$ is suitable to get drag coefficient $C_{D}$ of the scaled model. The area in table below is referring to the frontal area of the model as mentioned in chapter methodology. The summary of the test setup condition is shown in Table 1. The result for the test has been evaluated and graphs of drag force versus speed ${ }^{2}$ (Figure 1), drag coefficient $C_{D}$ versus speed (Figure 2), drag coefficient $C_{D}$ versus Reynolds number (Figure 3) have been plotted. Table 2 shows the drag coefficient $C_{D}$ from the experiment for five different speeds. The $C_{D}$ value for $10 \mathrm{~m} / \mathrm{s}$ speed is 0.395 . When speed is between $15 \mathrm{~m} / \mathrm{s}$ to $30.0 \mathrm{~m} / \mathrm{s}$ the drag coefficient $C_{D}$ become more lowers in the range 0.382 to 0.343 .

Table 1. Wind tunnel test setup conditions

\begin{tabular}{llll}
\hline Conditions & Speed $(\mathrm{m} / \mathrm{s})$ & Clearances $(\mathrm{m})$ & Area $\left(\mathrm{m}^{2}\right)$ \\
\hline $1^{\text {st }}$ & 10 & & \\
$2^{\text {nd }}$ & 15 & 0.012 & 0.01693 \\
$3^{\text {rd }}$ & 20 & & \\
$4^{\text {th }}$ & 25 & & \\
$5^{\text {th }}$ & 30 & & \\
\hline
\end{tabular}

Table 2. Result for five different speeds

\begin{tabular}{lllll}
\hline $\begin{array}{l}\text { Speed } \\
(\mathrm{m} / \mathrm{s})\end{array}$ & $\begin{array}{l}\text { Speed }^{2} \\
(\mathrm{~m} / \mathrm{s})\end{array}$ & $\begin{array}{c}\text { Drag force } \\
(\mathrm{N})\end{array}$ & $\begin{array}{l}\text { Drag } \\
\text { co-efficient, } \\
\mathrm{C}_{\mathrm{D}}\end{array}$ & $\begin{array}{l}\text { Reynolds } \\
\text { number, } \\
\mathrm{R}_{\mathrm{e}}\left(10^{5}\right)\end{array}$ \\
\hline 10 & 100 & 0.410 & 0.395 & 2.086 \\
15 & 225 & 0.891 & 0.382 & 3.129 \\
20 & 400 & 1.524 & 0.367 & 4,173 \\
25 & 625 & 2.241 & 0.346 & 5.216 \\
30 & 900 & 3.210 & 0.343 & 5.946 \\
\hline
\end{tabular}

Graph in Figure 1 for drag force versus speed ${ }^{2}$ shows a positive linear increment of drag force as the speed ${ }^{2}$ is increased. This proves the validity of the result where the drag force must be directly proportional to the speed. Graph in Figure 1 for drag force versus speed ${ }^{2}$ clearly shows drag force detected by three component balance increase proportionally to the wind speed in test section of 
wind tunnel. Logically when you increase the wind speed there will be greater axial force acting on the frontal area of the scaled model thus three component balances will detected force in sequence.

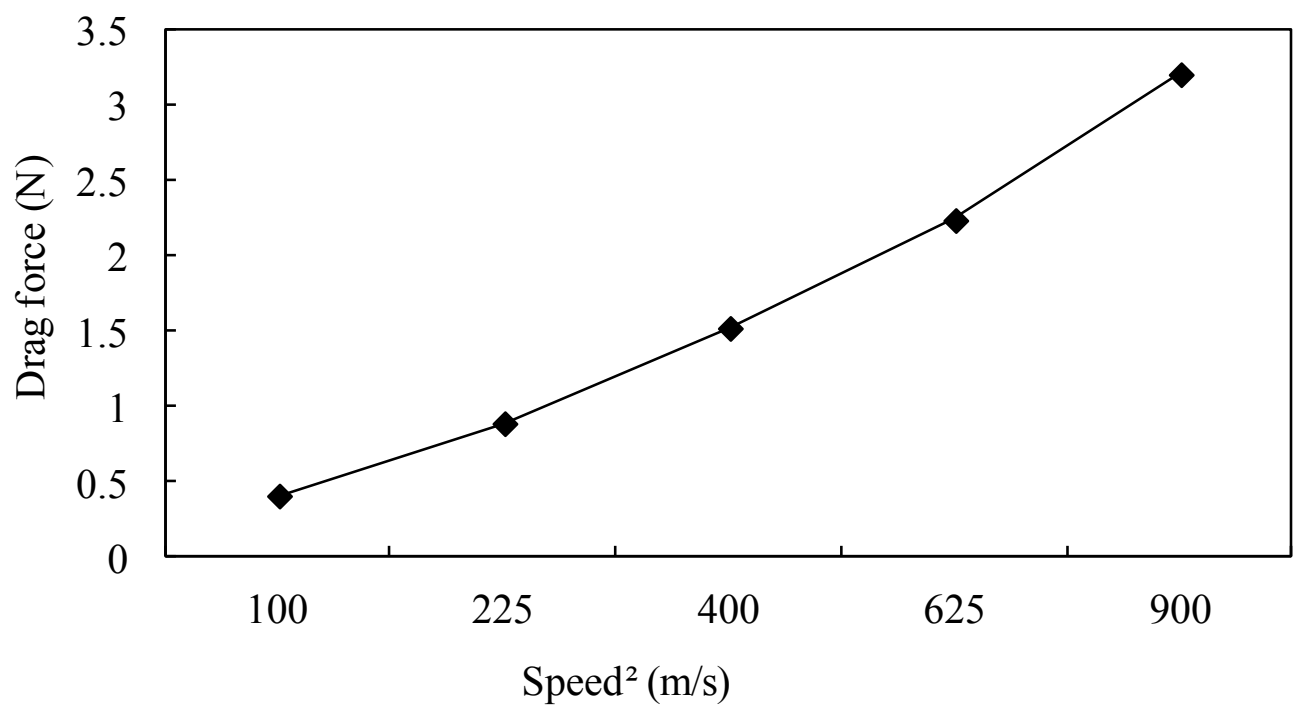

Figure 1. Graph of drag force versus speed ${ }^{2}$

Graph in Figure 2 shows the drag coefficient $C_{D}$ at corresponding speed. The $C_{D}$ value for $10 \mathrm{~m} / \mathrm{s}$ speed is 0.395 . At $15 \mathrm{~m} / \mathrm{s}$ speed to maximum speed $30 \mathrm{~m} / \mathrm{s}$, the drag coefficient $C_{D}$ became more stable in the range 0.367 to 0.343 . Graph in Figure 2 shows the drag coefficient $C_{D}$ versus speed. We can see that the drag coefficient $C_{D}$ varies with the wind speed in the test section. At $10 \mathrm{~m} / \mathrm{s}$ speed the drag coefficient $C_{D}$ is 0.395 . Then drag coefficient $C_{D}$ drop situation can be explained through air flow uniformly concept. The air flow in wind tunnel can be either uniform flow or nonuniform flow. Both flow are considered as unsteady flow rather than steady flow. This is because in real condition it is very rare to have steady flow. In this experiment the boundary layer is laminar over most of the length of the model.

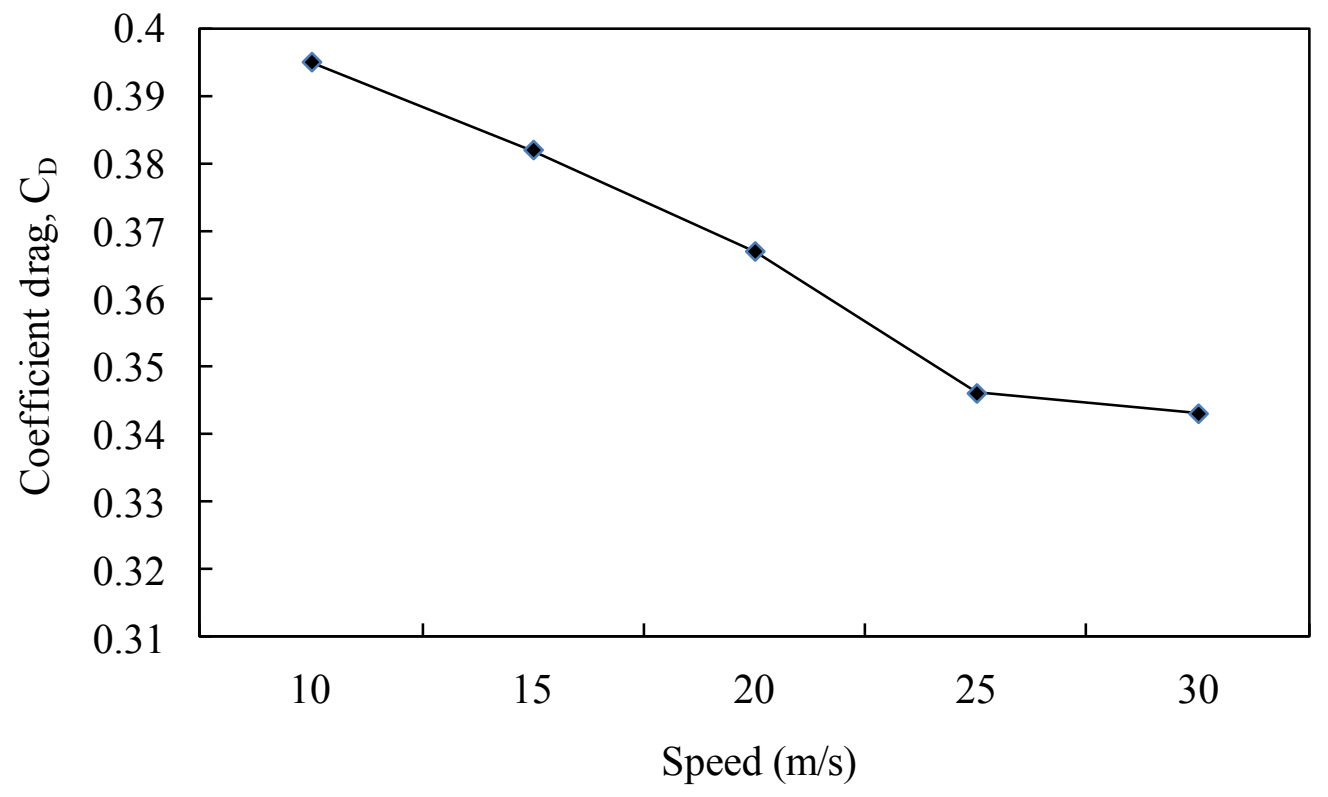

Figure 2. Graph of $C_{D}$ versus speed

It is believed there are some significance effects of air flow uniformity on the drag coefficient $C_{D}$ in this experiment. At the beginning of the experiment, the non-uniform flow which develops at 
very low speed of $10 \mathrm{~m} / \mathrm{s}$ created a higher value of drag coefficient $C_{D}$. However when the wind speed reached $15 \mathrm{~m} / \mathrm{s}$ to $30 \mathrm{~m} / \mathrm{s}$ the air flow became uniform and the drag coefficient $C_{D}$ decreased rapidly to constant value. The decreased of drag coefficient $C_{D}$ is due to the change of boundary layer thickness. Boundary layer thickness is small when non-uniform flow was formed at very low speed of the wind tunnel. This small boundary layer thickness has lot of energy which caused the drag coefficient $C_{D}$ higher in early of the experiment. In contrary boundary layer thickness is growing when uniform flow was formed at medium speed to maximum speed of the wind tunnel. This growing boundary layer has less energy which caused the drag coefficient $C_{D}$ to decrease and become constant.

Graph in Figure 3 drag coefficient $\mathrm{C}_{\mathrm{D}}$ versus Reynolds number $R_{e}$ shows a similarity pattern with graph of drag coefficient $\mathrm{C}_{\mathrm{D}}$ versus speed. The drag coefficient $\mathrm{C}_{\mathrm{D}}$ for $R_{e}$ number between 2.086 $\times 10^{5}$ to $5.946 \times 10^{5}$ are exactly the same with the drag coefficient $C_{D}$ for speed between $10 \mathrm{~m} / \mathrm{s}$ to $30 \mathrm{~m} / \mathrm{s}$. Graph in Figure 3 shows the drag coefficient $C_{D}$ versus Reynolds number. There is similarity between the graphs in Figure 3 (drag coefficient $C_{D}$ versus Reynolds number) and the graphs in Figure 2 (drag coefficient $C_{D}$ versus speed). The similarity between these two graphs is due to the Reynolds number is mostly depending on the air flow. In Reynolds number equation, density and viscosity of fluid properties are constant does not change. Only flow of the fluid change in the Reynolds number equation. Therefore the graphs in Figure 3 (drag coefficient $C_{D}$ versus Reynolds number) and the Figure 2 (drag coefficient $C_{D}$ versus speed) look very much alike.

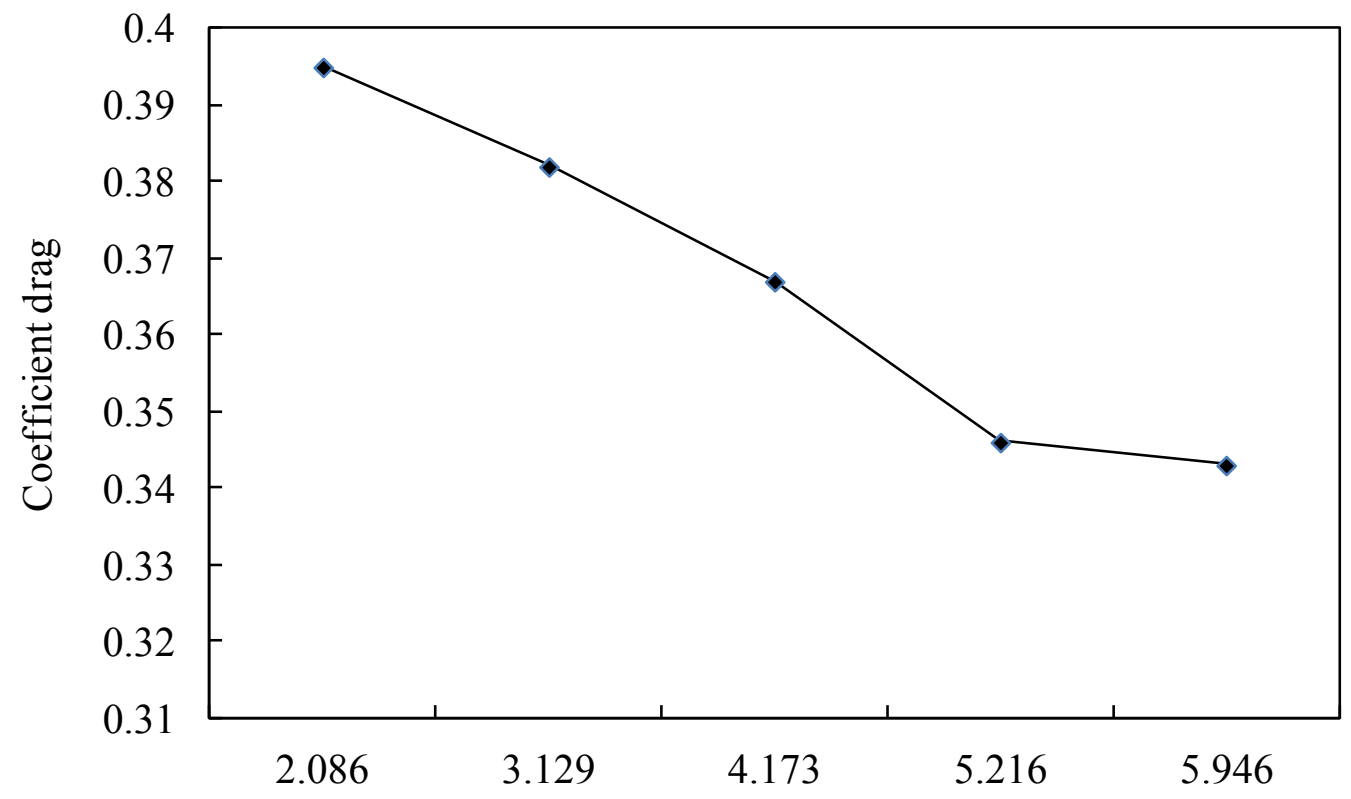

Reynolds number $\left(10^{\wedge} 5\right)$

Figure 3. Graph of drag coefficient $\mathrm{C}_{\mathrm{D}}$ versus Reynolds number $R_{e}$

\section{Conclusions}

The wind tunnel experimental was successfully achieved on the Proton PREVÊ. The value of drag coefficient that we get from this project is satisfied because in average of $0.345 C_{D}$.

\begin{tabular}{lll}
\hline $\begin{array}{l}\text { Wind Tunnel Speed } \\
(\mathrm{m} / \mathrm{s})\end{array}$ & Coefficient Drag $\mathrm{C}_{\mathrm{D}}$ & $\begin{array}{l}\text { Average Coefficient } \\
\text { Drag } \mathrm{C}_{\mathrm{D}}\end{array}$ \\
\hline 25 & 0.346 & 0.345 \\
30 & 0.343 & \\
\hline
\end{tabular}




\section{Acknowledgements}

The authors wish to thank the Faculty of Mechanical Engineering at the Universiti Teknologi Malaysia for their support and cooperation during this study. The authors also wish to thank Research Management Centre (RMC) for the Research University Grant (GUP-10J39) from the Universiti Teknologi Malaysia for their financial support.

\section{References}

[1] T. Lajos, Basics of vehicle aerodynamics, University of Rome La Sapienza (2002).

[2] M.I.M. Ramdzan, Aerodynamic forces of an oscillating airfoil, Universiti Teknologi Malaysia, Tesis Ijazah Sarjana Muda Mekanikal (2012).

[3] M.I. Hasssis, Kajian pekali seretan ke atas kereta perodua kancil, Universiti Teknologi Malaysia, Tesis Ijazah Sarjana Muda Mekanikal (2002).

[4] P. Incropera, P. DeWitt, Introduction to heat transfer, $5^{\text {th }}$ Edition, John Wiley \& Sons (Asia) Pte. Ltd. (2007).

[5] S.M. Hafis, M.J.M. Ridzuan, R.N. Farahana, A. Ayob, S. Syahrullail, Paraffinic mineral oil lubrication for cold forward extrusion: Effect of lubricant quantity and friction, Tribology International 60 (2013) 111-115.

[6] Y.A. Cengal, J. Cimbala, Fluid mechanic fundalmental and application, Thesis (2006). 